\title{
Н.В. Котляр
}

Владивостокский государственный университет экономики и сервиса Владивосток. Россия

\section{Создание вольно-пожарных обществ на дореволюционном Аальнем Востоке России (историко-правовой аспект)}

\begin{abstract}
Создание и деятельность вольно-пожарных обществ - Аобровольных частных легальных неполитических и непрофессиональных объединений, не преследующих целей прибыли, рассматриваются на основе текстов Устава Пожарного, вошедшего в состав Свода законов Российской империи 1857 г., уставов вольных пожарных обществ Аальнего Востока, Аокументов канцелярий губернаторов по поводу утверждения таковых обществ. Предметом исследования является создание таковых объединений: нормативно-правовой поряАок, предпосылки и условия начала деятельности. Хронологическими рамками работы является период 1896-1912 гг., на протяжении которого были отмечены случаи регистрации устава и/или начала Аеятельности вольно-пожарного общества. Затрагиваются следующие аспекты проблемы: изменения законодательства об обществах и союзах, состав вольно-пожарных обществ, сотрудничество обществ и местной власти, положение пожарного дела в различных городах дореволюционного Аальнего Востока. САелан вывод о значительной роли общественных сил в формировании системы противопожарной защиты, тушения пожаров и помощи пострадавшим дореволюционных городов.

Методологической основой исследования является принцип историзма, понимаемый как требование рассматривать изучаемый объект в становлении, развитии, взаимосвязи с другими явлениями, позво^яющий воссоздать целостное представление о создании общественных организаций, Аействующих в сфере предупреждения пожаров и пожаротушения. Среди общенаучных методов познания, применяемых автором, основное место занимают методы эмпирического и теоретического анализа, синтеза, индуктивных обобщений. СозАание общественных организаций изучается в рамках системного подхода, учитывая, что организации такого рода являются одним из элементов Аореволюционной системы противопожарных мер, включающих в себя законодательные нормы и процесс формирования безопасного городского быта.
\end{abstract}

Ключевые слова и словосочетания: правое положение общественных организаций, пожарное общество, вольно-пожарное общество, добровольное пожарное объединение, история пожарной службы, история Аореволюционного Аальнего Востока.

\section{N.V. Kotlyar}

Vladivostok State University of Economics and Service

Vladivostok. Russia

\section{The creation of the volunteer fire companies in the pre-revolutionary Russian Far East (historical and legal aspect)}

The establishment and operation of volunteer fire companies legal private voluntary non-political and nonprofessional associations that do not pursue profit objectives examined on the basis of the texts of the Charter of the fire, which became part of the laws of the Russian Empire, 1857, charters, voluntary fire companies of the Far East, documents of offices of governors regarding the approval of such societies. The subject of

Котляр Надежда Васильевна - канд. ист. наук, доцент кафедры теории и истории российского и зарубежного права Института права; e-mail: galactotes@gmail.com.

Nadezhda Vasilievna Kotlyar - Ph. D., Associate Professor of Chair of Theory and History of Russian and Foreign Law, Institute of Law. 
research is the creation of those associations: a legal procedure, conditions and terms of the beginning of the activity. Chronological framework of the work is the period 1896-1912., during which there were cases of registration of the Charter and/or commencement of volunteer fire companies. Addresses the following aspects of the problem: the law societies and unions, the composition of volunteer fire companies, cooperation companies and local authorities, the position of the fire in different cities of the pre-revolutionary far East. The conclusion about the important role of social forces in the formation of the fire protection system, fire fighting and aid to victims of pre-revolutionary cities.

Methodological basis of research is the principle of historicism, which is understood as the requirement to consider the studied phenomenon in the processes of formation, development, conjunction with other events, allowing you to recreate a holistic view on the establishment of public organizations operating in the field of fire prevention and fire fighting. Among the general scientific cognition methods used by the authors, the empirical and theoretical techniques for analysis, synthesis, inductive generalizations occupied center stage.

Keywords: right of public organizations, fire company, volunteer fire company, volunteer fire Association, history of the fire service, the history of pre-revolutionary Far East.

Развитие пожарной охраны в Российской империи берет свое начало в создании Российского пожарного общества (с 1901 г. - Императорского), образованного 14 июня 1892 г. по решению первого съезда русских деятелей пожарной охраны в Санкт-Петербурге. Российское пожарное общество стало общероссийским центром добровольной пожарной охраны, объединившим деятельность 250 вольных и 12 частных пожарных обществ, образованных к 1891 году [1, с. 66] на всем пространстве Российской империи. Опыт, накопленный противопожарной работой в дореволюционный период, важен для понимания новых акцентов в развитии современной пожарной службы и ее нормативно-правовой основы. Актуальным представляется изучение дореволюционного Дальнего Востока как примера сотрудничества общественных сил и городской власти, направленного на обеспечение противопожарной безопасности, создание и развитие системы противопожарной защиты, предупреждение о пожаре и тушение пожаров, помощь пострадавшим, страхование от огня и некоторые другие инициативы, способствующие развитию города и края.

Историография темы, таким образом, охватывает достаточно протяженный период времени - конца XIX - начала XXI века и открывается рядом работ, анализирующих правовое положение обществ и союзов и нормативно-правовую документацию частных объединений [2-4]. Среди немногочисленных публикаций дореволюционного времени следует особо отметить работу Н.П. Матвеева, содержащую наиболее полное описание общественной жизни отдельно взятого города [5]; проблемы общественной жизни городов Дальнего Востока на рубеже XIX-XX вв., в частности, вопросы пожарной службы, освещены в монографии А.М. Бодиско [6] и др. Интерес к обществам поднят в 1960-1970-х гг. в связи с выявлением особенностей правительственной политики в отношении организаций рабочих, открытием Народных домов, культурно-просветительской деятельностью. Особенно в этот период стоит отметить работы А.Д. Степанского, затрагивающего как правовой аспект существования организаций, так и характеристику сферы деятельности общества [7]. Наши современники пишут об общественных организациях как неотъемлемой части гражданского общества Российской империи, примером активной деятельности горожан и продуктивных отношений власти и общества. 
Стоит отметить работы А.С. Тумановой, посвященные правовым вопросами и фактам городского быта, характеризующим общественную жизнь во всей полноте [8]. В это время появились и публикации, специально посвященные деятельности пожарных дружин и вольных обществ, из которых назовем публикацию О.Б. Лынши о пожарном деле города Никольск-Уссурийского [9] и последовавшую за ней работу А.С. Коляды, А.М. Кузнецова [10]. Отметим коллективный труд авторов О.И. Сергеева, С.И. Лазаревой, Г.Я. Тригуба, посвященный истории самоуправления на Дальнем Востоке России, затрагивающий вопросы городской пожарной службы и формирования общественных противопожарных сил [11]. Интересны и недавние публикации в интернет-изданиях, основной характеристикой которых является обращение к истории пожарной службы города и ее формирования, в которой почетное место занимают вольные дружины противопожарных обществ [12, 13]. В целом, непродолжительное, около 40 лет, существование дореволюционных обществ на Дальнем Востоке и, в том числе, 25-летняя практика вольно-пожарных организаций, очевидно, обусловили незначительное количество исследований их создания и деятельности.

Регламентация организационной структуры и деятельности пожарных подразделений в стране осуществлялась указами второй половины XIX века, законодательно оформившими создание так называемых государственных пожарных команд и существование пожарных депо. В это же время особыми узаконениями жители городов освобождены от несения повинности тушения пожаров. Своего рода «кульминацией законодательной деятельности в сфере борьбы с пожарами этого времени можно назвать создание Устава Пожарного, вошедшего в состав Свода законов Российской Империи 1832 г., и его переработанное издание в составе Свода законов 1857 г.» [14]. С принятием в 1853 году «Нормального табеля состава пожарной части в городах» завершилось формирование организационной структуры профессиональной пожарной охраны, её штат стал определяться в зависимости от численности населения в населенном пункте [12]. Однако городские и сельские пожарные дружины не справлялись с угрозой пожаров, существовавшей на всем пространстве империи. Необходимы были новые формы организации борьбы с огнём, в том числе, и привлечение населения к борьбе с пожарами. Вольные пожарные общества представляли собой объединения обывателей-домовладельцев, целью которых было сохранить имущество или, по возможности, избежать больших убытков. Поддержка влиятельных горожан, сочувственность населения, крайняя заинтересованность владельцев домов - все это способствовало решению губернской власти разрешить создание такого рода общественных организаций. Общественные, добровольные пожарные дружины заняли свое место в хозяйственной системе города или села, составив неотъемлемую часть дореволюционной истории пожарной службы.

Законодательной основой для создания общественных пожарных организаций (обществ) в конце XIX века послужил Нормальный устав городских пожарных обществ, утвержденный 23 января 1896 г. и дополненный внесенными в него постановлениями Страхового Комитета 23 июня 1897 г., 29 июля 1890 г., 29 июля 
1890 г. соответственно. За утверждением Нормального устава последовали его дополнения. Для этой группы общественных организаций дополнения состояли в некотором упрощении процедуры создания вольно-пожарного общества. Например, в циркуляре МВД от 20 июня 1897 г. №22 сообщалось, что министерством был поднят вопрос об освобождении уставов подобных объединений от платы гербовых сборов «в целях содействия учреждению добровольных пожарных обществ и дружин в селениях» [4, с. 12], получивший положительное решение. Нормальные, примерные - это «образцовые» уставы, представляющие собой, по замыслу авторов, образец для написания устава, и на практике они были важнейшим условием, при соблюдении которого общество могло быть открыто. В порядке утверждения уставов обществ нормальный устав 1896 г. сделал самое важное с точки зрения упрощения процедуры открытия, а именно «признал возможным предоставить губернаторам разрешать учреждение городских пожарных обществ на точном основании упомянутого нормального устава, сообщая о каждом случае открытии в МВД» [3, с. 157].

4 марта 1906 года в соответствии с Манифестом 17 октября были изданы Временные правила об обществах и союзах, которые «утверждали условия пользования населением гражданскою свободою» [15]. Свобода выразилась в необязательном следовании «образцу» и обязательном утверждении устава особой инстанцией Губернским Присутствием по делам об обществах и союзах под председательством военного губернатора. Этот порядок касался и создания вольно-пожарных обществ - добровольных частных легальных неполитических и непрофессиональных объединений, не преследующих целей прибыли. Несомненно, положения «Свода уставов пожарных» 1857 г., объединив нормы и меры предостережения от пожаров, пожаротушения, розыска причин пожаров, возмещения убытков от пожаров, стали «фундаментом системы российского законодательства о пожарной безопасности в дореволюционный период» [14]. Однако с вступлением в действие Временных правил об обществах и союзах 4 марта 1906 г. «все прежние распоряжения правительства по делам частных обществ потеряли силу»; наряду с ними остались действовать нормальные, примерные и образцовые уставы $[4$, с. 3]. В такой ситуации применение Временных правил вызвало необходимость издать со стороны правительства новые разъяснения, как правило, неизвестные публике. Губернаторы допустили необычное для дореволюционной порядка послабление. Руководствуясь последними циркулями МВД и располагая всей необходимой информацией, губернаторские канцелярии принимали и допускали оба порядка создания и утверждения устава пожарных обществ: «с изданием Временных правил, пожарные общества могут возникать также в порядке сих правил» [3, с. 157], - пояснял один из авторитетных сборников законов и распоряжений правительства этого времени.

Ключевым вопросом для открытия дореволюционной общественной организации была формулировка уставной цели - учредители общественных организаций того времени скрывали второстепенные (политически неблагонадежные) цели создания общества, особенно, если текст устава значительно отступал от норматива. Вольно-пожарные общества, в которых состав учредителей и механизм участия 
Н.В. Котяяр. СозАание вольно-пожарных обществ на Аореволюционном Аальнем Востоке России...

в обществе практически исключал какую-либо неблагонадежность, опасения у властей не вызывали. Дело в том, что члены общества разделялись на лиц, «сделавших установленный денежный взнос или выполнивших безвозмездно какую-либо работу» [16, л. 583-584] - жертвователей и лиц, участвующих в тушении пожаров и заведующих делами общества - охотников, или действительных членов (цитируется по уставу Вольного Петропавловского городского пожарного общества). Известен даже такой факт: дружина Петропавловского вольно-пожарного общества, по уставу, полностью состояла из членов общества [16, л. 580-585].

Пожарные общества принадлежали к тому большинству общественных организаций дореволюционного времени, чьи уставы не только старательно повторяли текст Нормальных уставов, но и в качестве примера использовали уже утвержденный устав вольной дружины другого города. Кроме различающихся формулировок целей деятельности, отличались уставы вольных пожарных обществ незначительно. Например, § 23 в одном из уставов предполагает «учреждение отдела трубочистов», в другом «условия найма трубочистов»; огнеборцы - члены общества могли быть названы «дружиной» в одном уставе, или «командой»-в другом; должность врача общества (дружины) может быть предусмотрена уставом или вовсе не упоминаться в нем; 55 в разных уставах мог не допускать каких-либо лиц в состав общества или членов-охотников, выезжающих на тушение пожаров, не достигших 21 года или не имеющих согласие родителей, учащихся, состоящих на действительной службе и т.д. Впрочем, действия противопожарных обществ, учитывая полезность организаций, открывались немедленно, с разрешения генерал-губернатора Приамурского края. Например, устав Хабаровского вольного пожарного общества был утвержден в 21 ноября 1897 г., действия общества открыты в феврале 1896 г. [17], причем с начала создания организации правление общества помещалось в Хабаровском Окружном полицейском управлении [18]. К 21 ноября 1896 г., до утверждения устава, общество сформировало дружину из 44 человек и «пожарный обоз в составе одной машины - 35 ведер в минуту и 4-х резервных машин, принадлежащих торговым фирмам и отданных в распоряжение пожарного общества, также 1 багрового хода с баграми, лестницами, щитами и др. необходимых инструментов и 10 бочек с 2-колесными ходами; кроме того были построены зимние ходы под весь обоз и теплый сарай» [19].

Стремительность, с которой создавались вольно-пожарные общества, объясняется общими симпатиями горожан и множественной поддержкой. Например, в Хабаровске, «насколько выяснилась нужда в учреждении такого общества, можно заключить из того, что все представители крупных торговых фирм тут же подписали обязательство ежегодно вносить на это благое дело по 100 и даже по 125 р. ... Пожертвований поступило 2483 р.» [20]. Интересны предпосылки создания Никольского вольно-пожарного общества в 1899 г. Учитывая, что положение в городе было серьезным - почти половину убытков от пожаров на территории Приморской области составили 11 никольских пожаров [11, с. 145], - на Собрании уполномоченных городского правления «было постановлено предоставить обществу пользоваться участком городской пожарной команды» [10, с. 104, 107]. Инициатива создания 
пожарного общества, как и в остальных случаях, вышла «из среды влиятельных горожан» [21, с. 38]. В среде влиятельных горожан Благовещенска в 1899 г. был поднят вопрос об образовании вольной пожарной дружины из самих обывателей; «образование дружины прошло успешно, тем более, что наиболее влиятельные горожане взяли на себя и саму организацию этого нового дела» [21, с. 38].

Всего вольно-пожарных обществ на дореволюционном Дальнем Востоке насчитывалось 8 - по числу крупных городов и населенных пунктов. В общем, инициаторов и учредителей, чьи подписи стояли на письме-прошении к губернатору о создании организации, в период 1896-1912 гг. было от 30 до 40 человек, как уже было сказано, в основном домовладельцев. За время действия организаций, количество дружинников вольно-пожарного общества могло увеличиться до 73 человек (Владивосток). К 1917 г., например, каждый житель города Владивостока, из тех, кто вел активную общественную работу и состоял одновременно в двухтрех общественных организациях своего города, был членом вольно-пожарного общества Владивостока. По популярности у горожан вольно-пожарное общество не уступало даже самым многочисленным организациям в своем городе - собраниям, театральным, певческим, музыкальным обществам.

Кроме энергии и настойчивости учредителей, ставших предпосылкой создания общества, следует отметить, что идея создания вольно-пожарной дружины пользовалась общей поддержкой в городе ввиду неудовлетворительного состояния пожарного дела. «Сомнительные пожары, участившиеся в последнее время, уничтожают целые кварталы... за отсутствием противопожарных средств и связанных с ними мероприятий, нет никакой возможности спасать имущество», - объясняют представители дружины Иманского общества в письме, сопровождающем проект устава в 1912 г. [22, л. 62]. Сложная пожарная обстановка в сочетании с отсутствием противопожарных средств усугублялась общим невысоким уровнем жизни и городского быта. Частые и «сомнительные» пожары на Далекой окраине, помимо других причин, возникали от неосторожного обращения с керосиновыми лампами. В небольших дальневосточных городах, местечках, селах и деревнях, «не обслуживаемых электричеством и газовым освещением, доступным наиболее зажиточным слоям населения, пожарные случаи от воспламенения керосина в лампах прогрессивно увеличивались» [7, л. 113].

Вольно-пожарные общества были с радостью приняты городскими властями, решающими острую проблему противопожарных мер. В период создания вольных пожарных организаций или в предшествовавшее этому время отмечались «ничтожность городского пожарного обоза» во Владивостоке 1883 г. [5, с. 116]; имущество пожарного обоза, доставшееся Никольск-Уссурийску в наследство от села за десять лет существования обоза без постоянного присмотра пришло в упадок - «было ветхо и неисправно» [9, с. 4]; пожар в доме г-на Крета в 1899 г. в Хабаровске «показал, насколько неудовлетворительно в то время было поставлено в городе дело доставки воды на пожары и насколько недостаточно было количество инструментов противопожарного обоза» [6, с. 152-153]. Добровольные помощни- 
ки, работавшие наряду с городской пожарной командой, оказались незаменимы в решении важнейшей проблемы городского хозяйства.

Взаимодействие города и вольно-пожарного общества состояло в получении последним субсидий от города, пожарного имущества, передаваемого в ведение общества, участка земли для вольно-пожарной дружины или самого здания городской пожарной команды. Так, в 1899 г. хабаровская городская Дума, убедившись в неудовлетворительности пожарного дела, обратилась к местному обществу, точнее к гласным Думы, состоявшим в правлении общества (гласными были 5 из 8 членов правления общества) [19]. Комиссия, собравшаяся для подробного рассмотрения дела, постановила сдать в заведование обществу депо и строящуюся вторую пожарную каланчу, а также увеличить субсидию обществу с 500 р. до 3500 р., затем до 9000 р. [6, с. 165, 297]. Поддержание общества субсидиями и привлечение их к совместным действиям по улучшению пожарного дела проводились все время существования добровольных пожарных обществ, в которых дружина, инвентарь и затраты на них были значительно больше, чем мог потратить городской бюджет. В Хабаровске «полицейская пожарная команда стоит городу ежегодно, не считая обзаведения, от 10 до 12 тыс., причем, кроме кучеров, каланчиста и дневального... не может выставить более 4 чел. Общество же, при субсидии в 3500 р., и после затрат на постройку и лошадей даст при готовом уже обозе дружину в составе от 20 до 40 чел., работающих по охоте и хорошо подготовленных» [19]. Отметим, что сумма, отпущенная на содержание дружины общества, например в 1907 г., составила пособие размером в 9000 р. [6, с. 65, 267]. Со своей стороны учредители пожарных обществ, формулируя цель общества, могли предполагать высокую степень взаимодействия с городской пожарной дружиной: «тушение пожаров и вообще противодействие пожарным бедствиям в пределах города» (цитируется по уставу Вольного Петропавловского городского пожарного общества) [16, л. 583].

Следуя точному указанию Свода уставов пожарных 1857 г., заинтересованными в создании обществ должны быть страховые общества: «для вознаграждения убытков, претерпеваемых от пожаров, предоставляется застраховывать сгораемыя имущества в российских страховых от огня обществах, на основании их учреждения (ст. 92)» [23, отд. I, гл. V, с. 20.]. Действительно, вольно-пожарные общества не только предоставляли сведения о пожарах городским обществом взаимного от огня страхования (Хабаровск) [24, л. 49 об.], но даже способствовали созданию соответствующего общества: 23 августа 1911 г. Городская Дума Хабаровска избрала особую организационную комиссию для разработки организации в городе Общества взаимного от огня страхования [6, с. 272]. В течение нескольких лет после открытия, дальневосточные пожарные общества принимали в состав Российского союза обществ взаимного от огня страхования, уполномоченные которого могли производить осмотр городов, картами которых они располагали [24-27].

Современники в европейской части империи видели одну из главных мер по предупреждению пожаров в создании Особого противопожарного присутствия (прообраз Государственного пожарного надзора) - административной единицы, на которую возлагалась ответственность проводить проверку материалов дознания 
о причинах пожаров [10]. На Дальнем Востоке представление о причинах бедствия несколько отличалось. Рельеф местности, ветра и близкостоящие деревянные постройки создавали самую большую проблему дореволюционных дальневосточных городов - проблему оповещения о начале возгорания и незамедлительных действий по тушению. Свод уставов пожарных 1857 г. определял правила поведения при пожаре следующим образом: «...когда пожар начнется, давать звать о том у ближайшей будки городских стражам, ...до прибытия же пожарной команды употреблять все возможныя средства к прекращению пожара (ст. 42)» [23, отд. I, гл. II, с. 12]. На равнинной местности с вопросом предупреждения и оповещения справлялась наблюдательная башня при пожарной (полицейской) части, но дальневосточные сопки закрывали друг от друга районы города или отдельные здания. Вольные пожарные общества решали этот вопрос, помещая на домах членов общества знак в виде звезды, с тем чтобы любой мог звать на помощь дружинника. И, конечно, начинали строительство более высокого кирпичного здания пожарной каланчи или обзорной башни, соответствующей нуждам растущего города, часто совместно с городской Управой.

Вместе с тем уставы вольно-пожарных обществ дополняли и развивали направления действий, обозначенные в разделе «О мерах предосторожности от пожаров» Свода уставов пожарных 1857 г. Так, уже упоминавшийся пункт о создании или найме штата трубочистов исполнял положения ст. 32 Свода уставов пожарных: «владельцам домов вменяется в обязанность наблюдать, чтобы все дымовыя трубы в их домах были вычищаемы, по крайней мере, однажды в месяц» [23, отд. I, гл. II, c. 8]. Учитывая, что собственники домов, прежде всего, составляли штат дружинников пожарных обществ, закон исполнялся более отлаженным, коллективным решением. Акцент на мерах предосторожности от пожаров мог быть поставлен в уставной цели общества. Так, в уставе Никольского вольно-пожарного общества (с. Никольское - Никольск-Уссурийский) целью общества было «изыскание и развитие мер предупреждения и пресечения пожарных бедствий и доставление вспомоществования неимущим пожарным деятелям и лицам, пострадавшим от пожаров» [9, с. 12]. Такая формулировка обоснована: вольная дружина планировалась как помощь городской дружине, вызвала интерес жителей именно как мероприятие властей по усилению пожарной охраны.

Подводя итог вышесказанному, следует упомянуть о том, что жесткий характер норм, содержащихся в узаконениях, и особенность противопожарной сферы, в которой действовали подобные общественные организации, создали условия для появления такого рода обществ в дореволюционной России. Сопоставление текстов Устава пожарного, вошедшего в состав Свода законов Российской империи 1857 г., уставов вольных пожарных обществ Дальнего Востока, документов канцелярий губернаторов по поводу утверждения таковых обществ, позволяет сделать ряд выводов. Прежде всего, Свод уставов пожарных 1857 г. не только стал фундаментом системы законодательства о пожарной безопасности, но и дал нормы безопасного городского быта. Противопожарные условия, требования к пожаротушению и др. 
положения сначала легли в основу Нормальных уставов для вольно-пожарных дружин, а затем перешли в тексты уставов добровольных пожарных обществ.

В сотрудничестве с городской властью домовладельцы дополняли и развивали противопожарные меры, предусмотренные узаконениями, способствуя тому, что последние исполнялись более четко и отлажено, поскольку все этапы действий были коллективными и осуществлялись людьми, имеющими в своем распоряжении необходимую технику, средства и добровольно отвечающими за пожарную безопасность города. Стоит отметить, что идея вольно-пожарных обществ стала своевременным решением, позволившим вложить возможности обывателей в формирование городского пожарного хозяйства и улучшеить противопожарное дело. Развитие всей системы противопожарной защиты, тушения пожаров и помощи пострадавшим, полагающееся на общественные силы вольно-пожарных обществ, обществ страхования от огня и некоторых других добровольных объединений, составивших спектр общественных инициатив своего времени, способствовало органичному развитию города и края.

1. Байтало В.В., Калач Е.В. Российское Императорское пожарное общество на службе Отечества: первые шаги // Современные технологии обеспечения гражданской обороны и ликвидации последствий чрезвычайных ситуаций. 2015. Т. 2. № 1(6). С. 65-68.

2. Ануфриев П.Н. Правительственная регламентация образования частных обществ в России // Вопросы административного права. Кн. І. М., 1916. С. 15-44.

3. Ильинский К. Частныя общества: Сборник законов, распоряжений, правительства и решений Правительствующего Сената. Рига, 1913. 372 с., прил.

4. Плато Г.К. фон. Положения о частных обществах, учреждаемых с разрешения Министерств, Губернаторов и Градоначальников. Рига, 1903. 652 с.

5. Матвеев Н.П. Краткий исторический очерк г. Владивостока. Владивосток, 1900. 304 с.

6. Бодиско А.М. Из жизни Хабаровска. Хабаровск, 1915. 285 с.

7. Степанский А.Д. История общественных организаций дореволюционной России / под ред. д-ра ист. наук, проф. Н.П. Ерошкина. М., 1979. 79 с.

8. Туманова А.С. Общественные организации и русская публика в начале XX века. М.: Новый хронограф, 2008. 328 с.

9. Лынша О.Б. История пожарной службы города Уссурийска. Уссурийск, 1999. 166 с.

10. Коляда А.С., Кузнецов А.М. Никольск-Уссурийский: штрихи к портрету. Уссурийск, 1997.

11. Сергеев О.И., Лазарева С.И., Тригуб Г.Я. Местное самоуправление на Дальнем Востоке России во второй половине XIX-начале ХХ в.: Очерки истории. Владивосток, 2002. 296 с.

12. Историческая справка о становлении и развитии добровольной пожарной охраны ВДПО / Всероссийское добровольное пожарное объединение. Ишимское городское объединение [Электронный ресурc]. URL: http://vdpoishim.narod.ru/htmls/istoria.html

13. Императорское российское пожарное общество // Энциклопедия пожарной техники и оборудования. 2012 [Электронный ресурс]. URL: http://fire-truck.ru/encyclopedia/ imperatorskoe-rossiyskoe-pozharnoe-obshhestvo.html

14. Смирнова А.А., Опарина Т.И. Место пожарного устава в системе законодательства Российской Империи о пожарной безопасности // Вестник Санкт-Петербургского 
университета Государственной противопожарной службы МЧС России. Научноаналитический журнал 2013. № 3. С. 123-127.

15. Приамурские Ведомости. 1906. 29 апр. № 939

16. Российский государственный исторический архив Дальнего Востока (РГИА ДВ). Ф. 702. Оп. 3. Д. 384

17. Приамурские ведомости. 1901. 25 ноября. № 413.

18. Приамурские ведомости. 1896. 17 ноября. № 151.

19. Приамурские ведомости. 1901. 25 ноября. № 413.

20. Приамурские ведомости. 1896. 17 ноября. № 151.

21. Обзор Амурской области за 1899 г. Благовещенск, 1900. 45 с., прил.

22. РГИА ДВ. Ф. 702. Оп. 3. Д. 428.

23. Свод Законов Российской Империи, повелением Государя Императора Николая I составленный. Изд. 1857 г. Т. 12. Ч. 1. Уставы путей сообщения, почтовый, телеграфический, строительный и пожарный. Свод уставов пожарных. Спб., 1857. 664 с.

24. РГИА ДВ. Ф. 1276. Оп.1. Д.1.

25. РГИА ДВ. Ф. 702. ОП.3. Д. 5.

26. РГИА ДВ. Ф. 702. ОП.3. 435.

27. РГИА ДВ. Ф. 702. Оп.3. 490.

\section{Транслитерация}

1. Baitalo V.V., Kalach E.V. Rossiiskoe Imperatorskoe pozharnoe obshchestvo na sluzhbe Otechestva: pervye shagi, Sovremennye tekhnologii obespecheniya grazhdanskoi oborony i likvidatsii posledstvii chrezvychainykh situatsii, 2015, vol. 2, No 1(6), pp. 65-68.

2. Anufriev P.N. Pravitel'stvennaya reglamentatsiya obrazovaniya chastnykh obshchestv v Rossii // Voprosy administrativnogo prava. Kn. I. M., 1916, p. 15-44.

3. Il'inskii K. Chastnyya obshchestva. Sbornik zakonov, rasporyazhenii, pravitel'stva i reshenii Pravitel'stvuyushchego Senata. Riga, 1913, 372 pp., pril. p. 157

4. Plato G.K. fon. Polozheniya o chastnykh obshchestvakh, uchrezhdaemykh s razresheniya Ministerstv, Gubernatorov i Gradonachal'nikov. Riga, 1903, 652 p.

5. Matveev N.P. Kratkii istoricheskii ocherk g. Vladivostoka. Vladivostok, 1900, 304 p.

6. Bodisko A.M. Iz zhizni Khabarovska. Khabarovsk, 1915, 285 p.

7. Stepanskii A.D. Istoriya obshchestvennykh organizatsii dorevolyutsionnoi Rossii / pod red. d.i.n., prof. N.P. Eroshkina. M., 1979, 79 p.

8. Tumanova A.S. Obshchestvennye organizatsii i russkaya publika v nachale KhKh veka. M.: Novyi khronograf, 2008, 328 p.

9. Lynsha O.B. Istoriya pozharnoi sluzhby goroda Ussuriiska. Ussuriisk, 1999, 166 p.

10. Kolyada A.S., Kuznetsov A.M. Nikol'sk-Ussuriiskii: shtrikhi k portretu. Ussuriisk, 1997.

11. Sergeev O.I., Lazareva S.I., Trigub G.Ya. Mestnoe samoupravlenie na Dal'nem Vostoke Rossii vo vtoroi polovine KhIKh - nachale KhKh v.: Ocherki istorii. Vladivostok, 2002, 296 p.

12. Istoricheskaya spravka o stanovlenii i razvitii dobrovol'noi pozharnoi okhrany VDPO / Vserossiiskoe dobrovol'noe pozharnoe ob"edinenie. Ishimskoe gorodskoe ob"edinenie. URL: http://vdpoishim.narod.ru/htmls/istoria.html 
13. Imperatorskoe rossiiskoe pozharnoe obshchestvo // Entsiklopediya pozharnoi tekhniki i oborudovaniya. 2012, 26 marta. URL: http://fire-truck.ru/encyclopedia/imperatorskoerossiyskoe-pozharnoe-obshhestvo.html

14. Smirnova A.A., Oparina T.I. Mesto pozharnogo ustava v sisteme zakonodatel'stva Rossiiskoi Imperii o pozharnoi bezopasnosti, Vestnik Sankt-Peterburgskogo universiteta Gosudarstvennoi protivopozharnoi sluzhby MChS Rossii. Nauchno-analiticheskii zhurnal, 2013, No 3, pp. 123-127.

15. Priamurskie Vedomosti. 1906, 29 apr., No 939

16. Rossiiskii gosudarstvennyi istoricheskii arkhiv Dal'nego Vostoka (RGIA DV). F. 702. Op. 3. D. 384

17. Priamurskie vedomosti. 1901. 25 noyabrya. No 413.

18. Priamurskie vedomosti. 1896. 17 noyabrya. No 151.

19. Priamurskie vedomosti. 1901. 25 noyabrya. No 413.

20. Priamurskie vedomosti. 1896. 17 noyabrya. No 151.

21. Obzor Amurskoi oblasti za 1899 g. Blagoveshchensk, 1900. 45 p., pril.

22. RGIA DV. F. 702. Op. 3. D. 428.

23. Svod Zakonov Rossiiskoi Imperii, poveleniem Gosudarya Imperatora Nikolaya I sostavlennyi. Izd. 1857 g. T. 12. Ch. 1. Ustavy putei soobshcheniya, pochtovyi, telegraficheskii, stroitel'nyi i pozharnyi. Svod ustavov pozharnykh. Spb., 1857. 664 p.

24. RGIA DV. F. 1276. Op.1. D.1.

25. RGIA DV. F. 702. Op.3. D. 5.

26. RGIA DV. F. 702. Op.3. 435.

27. RGIA DV. F. 702. Op.3. 490.

\section{(C) Н.В. Котляр, 2018}

Для цитирования: Котляр Н.В. Создание вольно-пожарных обществ на дореволюционном Дальнем Востоке России (историко-правовой аспект) // Территория новых возможностей. Вестник Владивостокского государственного университета экономики и сервиса. 2018. Т. 10. № 2. C. 195-205.

For citation: Kotlyar N.V. The creation of the volunteer fire companies in the pre-revolutionary Russian Far East (historical and legal aspect), The Territory of New Opportunities. The Herald of Vladivostok State University of Economics and Service, 2018, Vol. 10, No 2, pp. 195-205.

DOI dx.doi.org/10.24866/VVSU/2073-3984/2018-2/195-205

Дата поступления: 28.05.2018. 